\title{
ANNOTATION
}

\section{Corneal Grafts}

It is said of Robert the Bruce that, noticing the spider so well known in folk-lore succeeding, after six attempts, in fixing a thread, he remarked " Now shall this spider teach me what I am to do, for I also have failed six times." For perseverance in an apparently almost hopeless task the spider is worthily rivalled by Mr. Tudor Thomas, whose efforts to obtain clear corneal grafts have lasted nine years. For this long period Thomas has fought against the technical difficulties of grafting one piece of avascular tissue into a similar piece of tissue in such a way as to retain transparency. In seven rabbits, operated upon by the latest and most successful technique, all the grafts healed: one was opaque, one showed a small central clear area and the remaining five were transparent or nearly so. It is true that the history of corneal transplantation is mainly a history of failure and it is true that Thomas's grafts were homoplastic, a method more likely to succeed than when heteroplastic grafts must be used, yet, in spite of all the lions in the path 'Thomas's work is one of constant progress in the surgical technique of an operation in which everything is against the surgeon. Viewing past efforts of science of all kinds in perspective, even during our own generation, we see that success generally follows effort and we may reasonably hope that what Thomas has succeeded in doing in the case of a rodent may ultimately become one of the many surgical successes when applied to man. Those who have seen Thomas's rabbits will undoubtedly share this hope : the photographs reproduced in the Lancet do no sort of justice to the original rabbits.

REFERENCE

Thomas, J. W. Tudor.-Successful grafting of the cornea in rabbits. Hunterian Lecture, Lancet, February 14, 1931.

\section{THE INTERNATIONAL ASSOCIATION FOR THE PREVENTION OF BLINDNESS}

The Second Annual Meeting of the Board of Governors of the International Association for the Prevention of Blindness was held on October 10, 1930, at the Palais des Académies in Brussels.

The President, Prof. de Lapersonne, was supported by the members of the Executive Committee and of the Bureau of the Secretariat, and there were also present representatives of many 